\title{
ERRATUM
}

\section{Holmes tremor: a delayed complication after resection of brainstem cavernomas}

TO THE READERSHIP: An error appeared in the article by Cenzato et al. (Cenzato M, Colistra D, Iacopino G, et al. Holmes tremor: a delayed complication after resection of brainstem cavernomas. J Neurosurg. Published online December 11, 2020. doi:10.3171/2020.7.JNS201352).

The legend to Figure 6 was incomplete. My drawing was inspired by a photograph of a cadaveric specimen prepared by Dr. Kaan Yağmurlu and published previously. To acknowledge this, the figure legend has been updated (see the figure here).

The article has been corrected online as of March 12, 2021.

Davide Colistra, MD

Great Metropolitan Hospital Niguarda, Milan, Italy

CORRESPONDING ARTICLE See pp 693-703.

INCLUDE WHEN CITING

Published online March 12, 2021; DOI: 10.3171/2021.2.JNS201352a.

CAANS 2021, except where prohibited by US copyright law

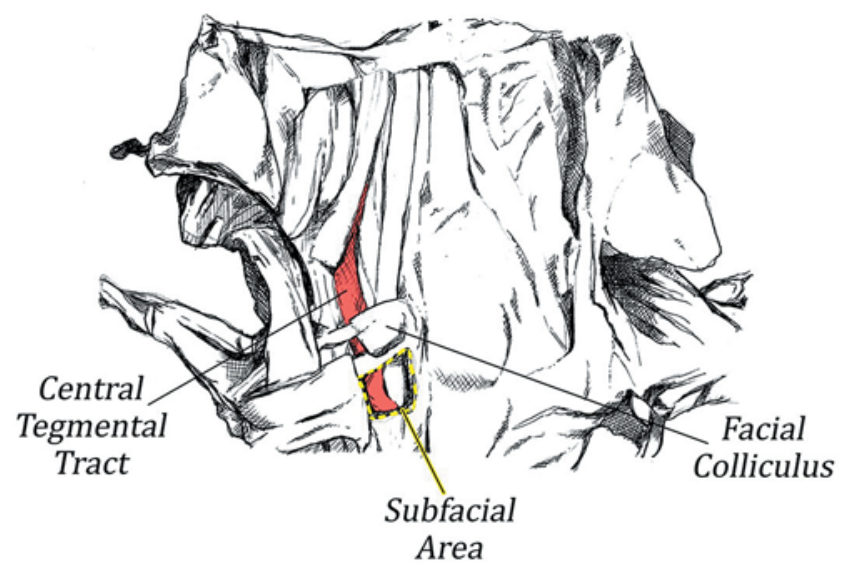

FIG. 6. Anatomical relationships between HT pathways and the subfacial SEZ. Freehand drawing showing how the central tegmental tract (red), within which the ROT runs, is at the level of the floor of the fourth ventricle just below the subfacial area (yellow), which is the SEZ used in case 4. Copyright for drawing: Davide Colistra; published with permission. The drawing is based on a photograph of a cadaveric dissection prepared by Kaan Yağmurlu, MD, which appears in The Rhoton Collection; with permission (CC BY-NC-SA 4.0 [http://creativecommons.org/ licenses/by-nc-sa/4.0]). Figure is available in color online only. 